\title{
Behavioral Factors Associated with Medication Nonadherence in Patients with Hypertension
}

\author{
Shu-Mei Chang ${ }^{1}$, I-Cheng $\mathrm{Lu}^{2,3}{ }^{\text {, Yi-Chun Chen }}{ }^{4, *}$, Chin-Feng Hsuan ${ }^{5,6}{ }^{(\mathbb{D}}$, Yin-Jin Lin $^{1}$ and Hung-Yi Chuang ${ }^{7,8} \mathbb{C D}^{-}$ \\ 1 Outpatient Department, E-DA Dachang Hospital, Kaohsiung 80794, Taiwan; ed109773@edah.org.tw (S.-M.C.); \\ ed106481@edah.org.tw (Y.-J.L.) \\ 2 Department of Occupational Medicine, E-DA Hospital, Kaohsiung 82445, Taiwan; ed102431@edah.org.tw \\ 3 School of Chinese Medicine for Post Baccalaureate, College of Medicine, I-Shou University, \\ Kaohsiung 82445, Taiwan \\ 4 Department of Health Management, College of Medicine, I-Shou University, Kaohsiung 82445, Taiwan \\ 5 Department of Cardiology, E-DA Hospital, Kaohsiung 82445, Taiwan; Calvin.hsuan@msa.hinet.net \\ 6 School of Medicine, College of Medicine, I-Shou University, Kaohsiung 82445, Taiwan \\ 7 Department of Public Health, Kaohsiung Medical University, Kaohsiung 80708, Taiwan; ericch@kmu.edu.tw \\ 8 Department of Environmental and Occupational Medicine, Kaohsiung Medical University Hospital, \\ Kaohsiung 80708, Taiwan \\ * Correspondence: kimi@isu.edu.tw
}

check for updates

Citation: Chang, S.-M.; Lu, I.-C.; Chen, Y.-C.; Hsuan, C.-F.; Lin, Y.-J.; Chuang, H.-Y. Behavioral Factors Associated with Medication Nonadherence in Patients with Hypertension. Int. J. Environ. Res. Public Health 2021, 18, 9614. https:/ / doi.org/10.3390/ijerph18189614

Academic Editors: Sara Rubinelli, Nicola Diviani and Claudia Zanini

Received: 3 July 2021

Accepted: 9 September 2021

Published: 12 September 2021

Publisher's Note: MDPI stays neutral with regard to jurisdictional claims in published maps and institutional affiliations.

Copyright: (c) 2021 by the authors. Licensee MDPI, Basel, Switzerland. This article is an open access article distributed under the terms and conditions of the Creative Commons Attribution (CC BY) license (https:/ / creativecommons.org/licenses/by/ $4.0 /)$.

\begin{abstract}
Medication nonadherence is associated with an increased risk of complications in hypertensive patients. We investigated behavioral factors associated with medication nonadherence in hypertensive patients in southern Taiwan. Using questionnaires, we collected data regarding clinicodemographic characteristics and nonadherence behaviors from 238 hypertensive patients. We assessed the self-reported prevalence of specific behaviors of medication nonadherence and investigated factors associated with each behavior using multivariable logistic regression analysis. The most common behavior of medication nonadherence was forgetting to take medication (28.6\%), followed by discontinuing medication $(9.2 \%)$ and reducing the medication dose $(8.8 \%)$. Age $\geq 65$ years (adjusted odds ratio $[\mathrm{aOR}]=0.32,95 \%$ confidence interval $[\mathrm{CI}]=0.15-0.69)$ and male sex $(\mathrm{aOR}=2.61$, $\mathrm{CI}=1.31-5.19)$ were associated with forgetting to take medication. The presence of comorbidities (diabetes, kidney disease, or both) and insomnia ( $\mathrm{aOR}=3.97,95 \% \mathrm{CI}=1.30-12.1$ ) was associated with reducing the medication dose. The use of diet supplements was associated with discontinuing the medication $(\mathrm{aOR}=4.82,95 \% \mathrm{CI}=1.50-15.5)$. Compliance with a low oil $/$ sugar $/$ sodium diet was a protective factor against discontinuing medication ( $\mathrm{aOR}=0.14 ; 95 \% \mathrm{CI}=0.03-0.75)$. The most pervasive behavior associated with medication nonadherence among hypertensive patients was forgetting to take medication. Age $<65$ years, male sex, comorbidities, insomnia, noncompliance with diet, and the use of dietary supplements were specifically associated with medication nonadherence.
\end{abstract}

Keywords: hypertension; medication adherence; patient compliance; comorbidities

\section{Introduction}

Hypertension is the main risk factor for cardiovascular disease, stroke, diabetes, and kidney disease worldwide [1], and its attributable burden of disease is greater than that of other risk factors, such as smoking and obesity [2]. It is a preventable disease that leads to significant disability and premature death [3], and adherence to its treatment protocol is essential to decrease the risk of complications, such as cardiovascular disease, cerebrovascular disease, diabetes, chronic kidney disease, and retinopathy [4-6]. However, medication nonadherence in patients with hypertension is a major public health issue. In this regard, a survey including 24 million patients with hypertension in the United States has shown that $31 \%$ were nonadherent to medication [7]. Furthermore, a meta-analysis of 28 studies from 15 countries reported that $45.2 \%$ of hypertensive patients and $31.2 \%$ of hypertensive patients with comorbidities did not comply with their antihypertensive drug 
regimen [8]. In Taiwan, poor medication adherence has been reported in approximately $15 \%$ of hypertensive patients and has been associated with an elevated risk of cardiovascular disease and all-cause hospitalizations [9].

Medication nonadherence among patients with hypertension has been associated with various factors [8,10-13]. Specifically, female sex, young age, number of drugs taken, smoking, the use of complementary and alternative medicine, and the presence of comorbidities have all been associated with an increased risk of noncompliance $[8,10,11,13]$, whereas low salt intake and adequate exercise have been proposed as protective factors [12]. However, the association between demographic characteristics or lifestyle habits and medication nonadherence has not been consistent in previous studies, probably due to differences in ethnicity, culture, and health literacy among the populations studied, as well as the use of disparate measurement methods, such as pill counting and the Morisky medication adherence scale-8 [2,14-16]. In addition, it is unknown whether specific factors are related to particular behaviors, such as forgetting to take the medication, reducing the medication dose, or discontinuing the medication.

This study therefore aimed to investigate factors associated with nonadherence behaviors in relation to antihypertensive medication (forgetting to take the medication, reducing the medication dose, and discontinuing the medication). Additionally, we compared the differences in medication nonadherence between hypertensive patients with comorbidities (diabetes, kidney disease, or both) and hypertensive patients without comorbidities.

\section{Materials and Methods}

\subsection{Study Participants}

This cross-sectional study included patients aged 40 years or older diagnosed with hypertension with or without comorbidities (diabetes, kidney diseases, or both) and under antihypertensive medication for at least one year at the time of the assessment. Between January and December 2020, a trained and experienced interviewer approached patients at the waiting areas of three hospitals located in southern Taiwan and invited them to answer structured questionnaires if they fit the inclusion criteria. Two hundred and seventy-nine invited patients participated in this study; however, 41 patients were rejected during the interview. Overall, 141 hypertensive patients without comorbidities and 97 hypertensive patients with comorbidities were interviewed. This study was conducted in line with the principles of the Declaration of Helsinki and was approved by the Research Ethics Committee of E-Da Hospital (approval No. EMRP-108-065). The interviews were conducted with the understanding and the consent of each participant.

\subsection{Data Collection}

Ad hoc structured questionnaires were designed to collect information on demographic variables (age, sex, education, marital status), lifestyle habits (exercise, smoking, alcohol consumption, compliance with a low oil/sugar/sodium diet, use of dietary supplements), sleep condition, physical/mental health awareness, medication status (number of drugs taken and number of medication doses per day), and medication nonadherence. Medication nonadherence was evaluated by asking participants if the following behaviors occurred more than twice a week within the previous 3 months (with answers as "Yes" or "No"): Forgetting to take medication, reducing the medication dose, and discontinuing the medication. This questionnaire was self-developed according to previous literature [11-15] and clinical experiences, and the content validity was checked by five experts in the field to assess the usability, clarity, relevance, and comprehensibility of the content and questions (Figure S1).

\subsection{Data Analysis}

We calculated the frequencies of demographic characteristics, physical/mental health awareness, medication status, and medication nonadherence by univariate analysis, and compared the differences between participants with and without comorbidities using the 
chi-square test. The association between medication nonadherence and demographic variables, lifestyle habits, sleeping time, physical/mental health awareness, and medication status was assessed using the chi-square test. We used multivariable logistic regression analysis to investigate the association between specific behaviors of nonadherence and various factors; we considered age, sex, education level, marital status, presence of comorbidities, sleep condition, physical/mental health awareness, compliance with a low oil/sugar/sodium diet, and the use of dietary supplements as the independent variables.

The odds ratios (ORs) and 95\% confidence intervals (CIs) were calculated and presented. The absence of comorbidities, age $<65$ years, female sex, education $<9$ years, married status, sleeping $\geq 7 \mathrm{~h}$ a day, good physical/mental health awareness, noncompliance with low oil/sugar/sodium diet, and no dietary supplementation were used as references in the multivariable logistic regression analysis. Data analysis was performed using SPSS software version 18 (IBM Corp., Armonk, NY, USA); the $\alpha$ value was set at 0.05 . The conceptual framework is shown in Figure 1.

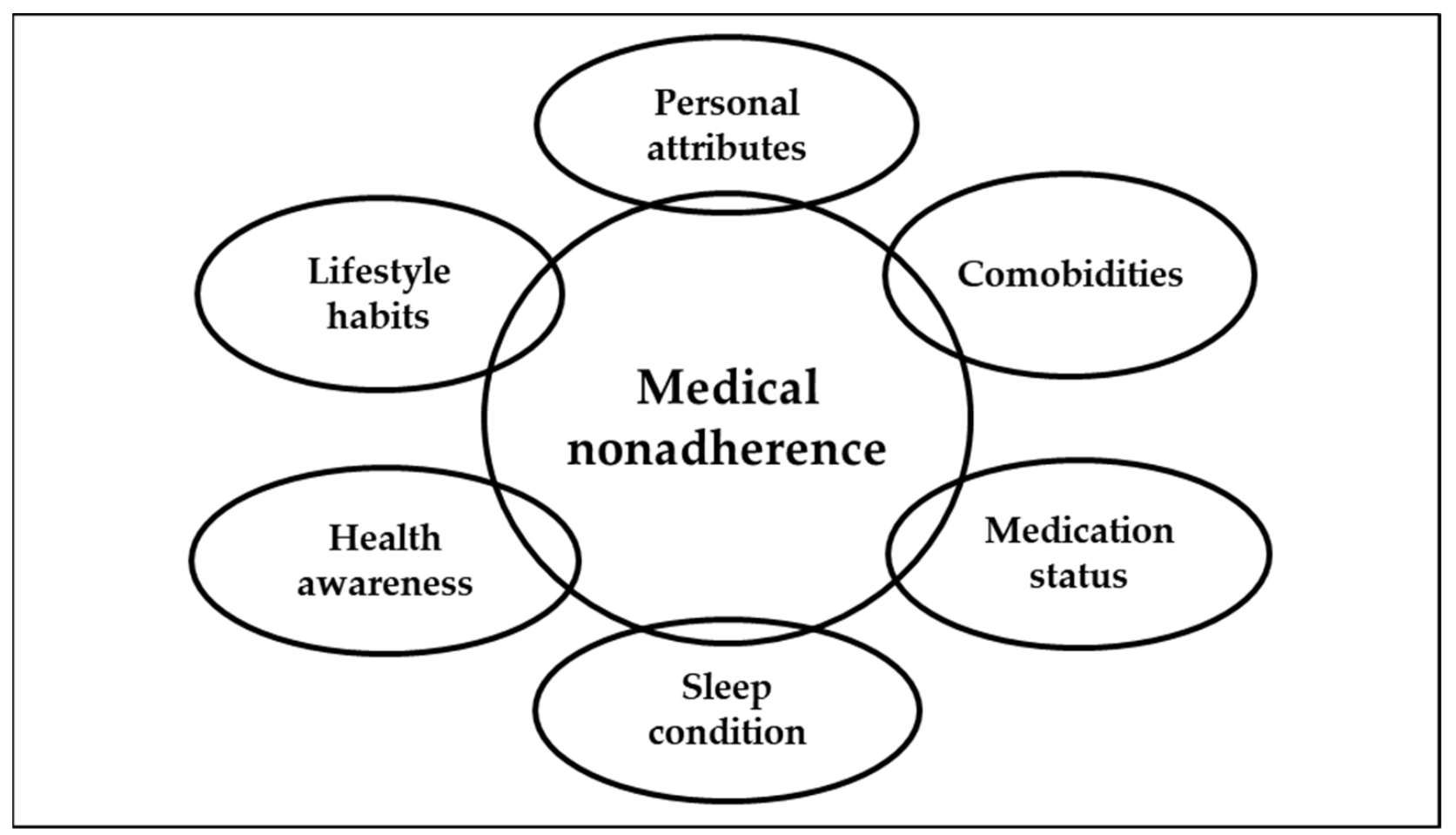

Figure 1. The considered factors associated with medical nonadherence.

\section{Results}

\subsection{Characteristics of the Included Hypertensive Patients}

Of the 238 patients in this study, $54.6 \%$ were male, $44.3 \%$ were aged 65 years or older, and $73.8 \%$ were married. Additionally, 38.2\% took more than three pills a day, and $66.4 \%$ took medication once a day (Table 1). Patients with comorbidities were more likely than patients without comorbidities to take more than three pills a day and to take medication more than once a day $(54.2 \%$ vs. $28.7 \%$ and $43.3 \%$ vs. $27.0 \%$, respectively; $p<0.05$ for both comparisons). Forgetting to take medication (28.6\%) was the most frequent behavior of medication nonadherence. 
Table 1. Baseline characteristics and behaviors of nonadherence in the total cohort and in patients with or without comorbidities *.

\begin{tabular}{|c|c|c|c|c|}
\hline \multirow{3}{*}{ Variables } & \multicolumn{2}{|c|}{ Comorbidities * } & \multirow[t]{2}{*}{$p$-Value } & \multirow[t]{2}{*}{ Total } \\
\hline & No & Yes & & \\
\hline & $n(\%)$ & $n(\%)$ & & $n(\%)$ \\
\hline Age, years $(n=235)$ & & & 0.233 & \\
\hline$<65$ & $82(59.0)$ & $49(51.0)$ & & $131(55.7)$ \\
\hline$\geq 65$ & $57(54.8)$ & $47(49.0)$ & & $104(44.3)$ \\
\hline $\operatorname{Sex}(n=238)$ & & & 0.895 & \\
\hline Female & $63(44.7)$ & $45(46.4)$ & & $108(45.4)$ \\
\hline Male & $78(55.3)$ & $52(53.6)$ & & $130(54.6)$ \\
\hline Education, years $(n=237)$ & & & 0.407 & \\
\hline$<9$ & $50(35.5)$ & $37(38.5)$ & & $87(36.7)$ \\
\hline $10-12$ & $45(31.9)$ & $23(24.0)$ & & $68(28.7)$ \\
\hline$\leq 12$ & $46(32.6)$ & $36(37.5)$ & & $82(34.6)$ \\
\hline Marital status $(n=237)$ & & & 0.881 & \\
\hline Married & $104(74.3)$ & $71(73.2)$ & & $175(73.8)$ \\
\hline Other & $36(25.7)$ & $26(26.8)$ & & $62(26.1)$ \\
\hline Physical health awareness $(n=238)$ & & & 0.219 & \\
\hline Normal/good & $121(85.8)$ & $89(91.8)$ & & $210(88.2)$ \\
\hline Poor & $20(14.2)$ & $8(8.2)$ & & $28(11.8)$ \\
\hline Mental health awareness $(n=238)$ & & & 0.869 & \\
\hline Normal/good & $114(80.9)$ & $77(79.3)$ & & $191(80.3)$ \\
\hline Poor & $27(19.1)$ & $20(20.6)$ & & $47(19.7)$ \\
\hline Sleep condition $(n=237)$ & & & 0.355 & \\
\hline$>7 \mathrm{~h}$ a day & $72(51.1)$ & $58(60.4)$ & & $130(54.9)$ \\
\hline$<7 \mathrm{~h}$ a day & $61(43.3)$ & $33(34.4)$ & & $94(39.7)$ \\
\hline Insomnia & $8(5.7)$ & $5(5.2)$ & & $13(5.5)$ \\
\hline Exercise $(n=238)$ & & & 0.889 & \\
\hline No & $46(32.6)$ & $33(34.0)$ & & $79(33.2)$ \\
\hline Yes & $95(67.4)$ & $64(66.0)$ & & $159(66.8)$ \\
\hline Smoking $(n=238)$ & & & 0.573 & \\
\hline No & $119(84.4)$ & $85(87.6)$ & & $204(85.7)$ \\
\hline Yes & $22(15.6)$ & $12(12.4)$ & & $34(14.3)$ \\
\hline Alcohol consumption $(n=238)$ & & & 0.763 & \\
\hline No & $105(74.5)$ & $74(76.3)$ & & $179(75.2)$ \\
\hline Often/occasionally & $36(25.5)$ & $23(23.7)$ & & $59(24.8)$ \\
\hline $\begin{array}{c}\text { Compliance with low oil/sugar/sodium diet }(n= \\
\text { 238) }\end{array}$ & & & 0.113 & \\
\hline Never & $10(7.1)$ & $15(15.5)$ & & $25(10.5)$ \\
\hline Often & $60(42.6)$ & $36(37.1)$ & & $96(40.3)$ \\
\hline Always & $71(50.4)$ & $46(47.4)$ & & $117(49.2)$ \\
\hline Use of dietary supplements $(n=237)$ & & & 1.00 & \\
\hline No & $68(48.2)$ & $47(49.0)$ & & $115(48.5)$ \\
\hline Yes & $73(51.8)$ & $49(51.0)$ & & $122(51.5)$ \\
\hline Number of drugs $(n=232)$ & & & $<0.001$ & \\
\hline$<3$ & $97(71.3)$ & $44(45.8)$ & & $141(59.2)$ \\
\hline$>3$ & $39(28.7)$ & $52(54.2)$ & & $91(38.2)$ \\
\hline Number of Medication doses per day $(n=238)$ & & & 0.012 & \\
\hline 1 & $103(73.0)$ & $55(56.7)$ & & $158(66.4)$ \\
\hline$>1$ & $38(27.0)$ & $42(43.3)$ & & $80(33.6)$ \\
\hline
\end{tabular}


Table 1. Cont.

\begin{tabular}{|c|c|c|c|c|}
\hline \multirow{3}{*}{ Variables } & \multicolumn{2}{|c|}{ Comorbidities * } & \multirow[t]{2}{*}{$p$-Value } & \multirow[t]{2}{*}{ Total } \\
\hline & No & Yes & & \\
\hline & $n(\%)$ & $n(\%)$ & & $n(\%)$ \\
\hline Forgetting to take medication $(n=238)$ & & & 0.058 & \\
\hline No & $94(66.7)$ & $76(78.4)$ & & $170(71.4)$ \\
\hline Yes & $47(33.3)$ & $21(21.6)$ & & $68(28.6)$ \\
\hline Reducing the dose $(n=236)$ & & & 0.061 & \\
\hline No & $131(94.2)$ & $84(86.6)$ & & $215(90.3)$ \\
\hline Yes & $8(5.8)$ & $13(13.4)$ & & $21(8.8)$ \\
\hline Discontinuing medication $(n=238)$ & & & 0.255 & \\
\hline No & $125(88.7)$ & $91(93.8)$ & & $216(90.8)$ \\
\hline Yes & $16(11.3)$ & $6(6.2)$ & & $22(9.2)$ \\
\hline
\end{tabular}

${ }^{*}$ Diabetes, kidney disease, or both.

\subsection{Factors Associated with Behaviors of Nonadherence}

Table 2 shows the frequency of behaviors of nonadherence according to different variables. Age $<65$ years, male sex, marital status other than married, and alcohol consumption were associated with forgetting to take medication. Reduced sleeping time and multiple daily doses were associated with reducing the medication dose.

Table 2. Distribution of behaviors of nonadherence to medication according to demographic variables, lifestyle habits, sleep condition, physical/mental health awareness, and medication status.

\begin{tabular}{|c|c|c|c|c|c|c|}
\hline \multirow{3}{*}{ Variables } & \multicolumn{6}{|c|}{ Medication Nonadherence Behaviors * } \\
\hline & \multicolumn{2}{|c|}{ Forgetting to Take Medication } & \multicolumn{2}{|c|}{ Reducing Medication Dose } & \multicolumn{2}{|c|}{ Discontinuing Medication } \\
\hline & No & Yes & No & Yes & No & Yes \\
\hline \multicolumn{7}{|l|}{ Age, years } \\
\hline$<65$ & $80(61.1)$ & $51(38.9)$ & $121(93.1)$ & $9(6.9)$ & $117(89.3)$ & $14(10.7)$ \\
\hline$\geq 65$ & $89(85.6)$ & $15(14.4)$ & $92(89.3)$ & $11(10.7)$ & $98(94.2)$ & $6(5.8)$ \\
\hline$p$-value & $<0.001$ & & 0.351 & & 0.240 & \\
\hline \multicolumn{7}{|l|}{ Sex } \\
\hline Female & $90(83.3)$ & $18(16.7)$ & $99(92.5)$ & $8(7.5)$ & $99(91.7)$ & $9(8.3)$ \\
\hline Male & $80(61.5)$ & $50(38.5)$ & $116(89.9)$ & $13(10.1)$ & $117(90.0)$ & $13(10.0)$ \\
\hline$p$-value & $<0.001$ & & 0.647 & & 0.823 & \\
\hline \multicolumn{7}{|l|}{ Education, years } \\
\hline$\leq 9$ & $69(79.3)$ & $18(20.7)$ & $76(88.4)$ & $10(11.6)$ & $80(92.0)$ & $7(8.0)$ \\
\hline $10-12$ & $43(63.2)$ & $25(36.8)$ & $63(94.0)$ & $4(6.0)$ & $64(94.1)$ & $4(5.9)$ \\
\hline$>12$ & $57(69.5)$ & $25(30.5)$ & $76(92.7)$ & $6(7.3)$ & $71(86.6)$ & $11(13.4)$ \\
\hline$p$-value & 0.081 & & 0.411 & & 0.252 & \\
\hline \multicolumn{7}{|l|}{ Marital status } \\
\hline Married & $134(76.6)$ & $41(23.4)$ & $154(88.5)$ & $20(11.5)$ & $157(89.7)$ & $18(10.3)$ \\
\hline Other & $36(58.1)$ & $26(41.9)$ & $61(98.4)$ & $1(1.6)$ & $58(93.5)$ & $4(6.5)$ \\
\hline$p$-value & 0.008 & & 0.018 & & 0.454 & \\
\hline \multicolumn{7}{|c|}{ Physical health awareness } \\
\hline Normal/Good & $149(71.0)$ & $61(29.0)$ & $192(91.9)$ & $17(8.1)$ & $192(91.4)$ & $18(8.6)$ \\
\hline Poor & $21(75.0)$ & $7(25.0)$ & $23(85.2)$ & $4(14.8)$ & $24(85.7)$ & $4(14.3)$ \\
\hline$p$-value & 0.824 & & 0.275 & & 0.305 & \\
\hline \multicolumn{7}{|c|}{ Mental health awareness } \\
\hline Normal/Good & $136(71.2)$ & $55(28.8)$ & $174(92.1)$ & $15(7.9)$ & $176(92.1)$ & $15(7.9)$ \\
\hline Poor & $34(72.3)$ & $13(27.7)$ & $41(87.2)$ & $6(12.8)$ & $40(18.5)$ & $7(14.9)$ \\
\hline$p$-value & 1.00 & & 0.388 & & 0.159 & \\
\hline
\end{tabular}


Table 2. Cont.

\begin{tabular}{|c|c|c|c|c|c|c|}
\hline \multirow{3}{*}{ Variables } & \multicolumn{6}{|c|}{ Medication Nonadherence Behaviors * } \\
\hline & \multicolumn{2}{|c|}{ Forgetting to Take Medication } & \multicolumn{2}{|c|}{ Reducing Medication Dose } & \multicolumn{2}{|c|}{ Discontinuing Medication } \\
\hline & No & Yes & No & Yes & No & Yes \\
\hline \multicolumn{7}{|l|}{ Sleeping time } \\
\hline$>7 \mathrm{~h}$ a day & $90(69.2)$ & $40(30.8)$ & $124(96.1)$ & $5(3.9)$ & $120(92.3)$ & $10(7.7)$ \\
\hline$<7 \mathrm{~h}$ a day & $69(73.4)$ & $25(26.6)$ & $80(86.0)$ & $13(14.0)$ & $84(89.4)$ & $10(10.6)$ \\
\hline Insomnia & $10(76.9)$ & $3(23.1)$ & $10(76.9)$ & $3(23.1)$ & $11(84.6)$ & $2(15.4)$ \\
\hline$p$-value & 0.713 & & 0.006 & & 0.557 & \\
\hline \multicolumn{7}{|l|}{ Exercise } \\
\hline No & $53(67.1)$ & $26(32.9)$ & $72(92.3)$ & $6(7.7)$ & $70(88.6)$ & $9(11.4)$ \\
\hline Yes & $117(73.6)$ & $42(26.4)$ & $143(90.5)$ & $15(9.5)$ & $146(91.8)$ & $13(8.2)$ \\
\hline$p$-value & 0.361 & & 0.809 & & 0.478 & \\
\hline \multicolumn{7}{|l|}{ Smoking } \\
\hline No & $150(73.5)$ & $54(26.5)$ & 181 (89.6) & $21(10.4)$ & 187 (91.7) & $17(8.3)$ \\
\hline Yes & $20(58.8)$ & $14(41.2)$ & $34(100.0)$ & $0(0.0)$ & $29(85.3)$ & $5(14.7)$ \\
\hline$p$-value & 0.100 & & 0.051 & & 0.216 & \\
\hline \multicolumn{7}{|l|}{ Alcohol } \\
\hline No & $136(76.0)$ & $43(24.0)$ & $162(91.5)$ & $15(8.5)$ & $166(92.7)$ & $13(7.3)$ \\
\hline Yes & $34(57.6)$ & $25(42.4)$ & $53(89.8)$ & $6(10.2)$ & $50(84.7)$ & $9(15.3)$ \\
\hline$p$-value & 0.012 & & 0.792 & & 0.074 & \\
\hline \multicolumn{7}{|c|}{$\begin{array}{l}\text { Compliance with low } \\
\text { oil/sugar/sodium diet }\end{array}$} \\
\hline Never & $17(68.0)$ & $8(32.0)$ & $24(96.0)$ & $1(4.0)$ & $21(84.0)$ & $4(16.0)$ \\
\hline Often & $65(67.7)$ & $31(32.3)$ & $85(90.4)$ & $9(9.6)$ & 87 (90.6) & $9(9.4)$ \\
\hline Always & 88 (75.2) & $29(24.8)$ & $106(90.6)$ & $11(9.4)$ & $108(92.3)$ & $9(7.7)$ \\
\hline$p$-value & 0.446 & & 0.660 & & 0.428 & \\
\hline \multicolumn{7}{|c|}{ Use of dietary supplements } \\
\hline No & $82(71.3)$ & $33(28.7)$ & 107 (93.9) & $7(6.1)$ & $108(93.9)$ & $7(6.1)$ \\
\hline Yes & $88(72.1)$ & $34(27.9)$ & $107(88.4)$ & $14(11.6)$ & $107(87.7)$ & $15(12.3)$ \\
\hline$p$-value & 1.00 & & 0.173 & & 0.119 & \\
\hline \multicolumn{7}{|c|}{ Number of drugs } \\
\hline$\leq 3$ & $97(68.8)$ & $44(31.2)$ & 129 (91.5) & $12(8.5)$ & $124(87.9)$ & $17(12.1)$ \\
\hline$>3$ & $70(76.9)$ & $21(23.1)$ & $81(91.0)$ & $8(9.0)$ & $86(94.5)$ & $5(5.5)$ \\
\hline$p$-value & 0.231 & & 1.00 & & 0.112 & \\
\hline \multicolumn{7}{|c|}{$\begin{array}{l}\text { Number of Medication doses } \\
\text { per day }\end{array}$} \\
\hline 1 & $112(70.9)$ & $46(29.1)$ & $148(94.3)$ & $9(5.7)$ & $146(92.4)$ & $12(7.6)$ \\
\hline$>1$ & $58(72.5)$ & $22(27.5)$ & $67(84.8)$ & $12(15.2)$ & $70(87.5)$ & $10(12.5)$ \\
\hline$p$-value & 0.880 & & 0.027 & & 0.240 & \\
\hline
\end{tabular}

${ }^{*}$ Data are shown as $\mathrm{n}(\%)$. All comparisons were performed using the chi-square test.

Table 3 shows the results of multivariable logistic regression analysis to identify factors associated with behaviors of medication nonadherence. Age $\geq 65$ years constituted a protective factor for forgetting to take medication (adjusted OR $[\mathrm{aOR}]=0.32,95 \% \mathrm{CI}=0.15-0.69$ ); however, male sex $(\mathrm{aOR}=2.61,95 \% \mathrm{CI}=1.31-5.19)$ was associated with forgetting to take medication. Additionally, the presence of comorbidities $(\mathrm{aOR}=3.97,95 \% \mathrm{CI}=1.30-12.1)$ was associated with reducing the medication dose. Reducing the medication dose was also associated with sleeping $<7 \mathrm{~h}$ a day $(\mathrm{aOR}=4.68,95 \% \mathrm{CI}=1.42-15.4)$ and insomnia (aOR $=7.89,95 \% \mathrm{CI}=1.22-51.3)$. Good compliance with a low oil/sugar/sodium diet was associated with a lower risk of discontinuing medication $(\mathrm{aOR}=0.14,95 \% \mathrm{CI}=0.03-0.75)$. 
Table 3. Multivariable logistic regression analysis of factors associated with specific behaviors of nonadherence to antihypertensive medication.

\begin{tabular}{|c|c|c|c|}
\hline \multirow{3}{*}{ Variables } & \multicolumn{3}{|c|}{ Medication Nonadherence Behaviors } \\
\hline & Forgetting to Take Medication & Reducing Medication Dose & Discontinuing Medication \\
\hline & OR $(95 \% \mathrm{CI})$ & OR $(95 \%$ CI $)$ & OR $(95 \%$ CI $)$ \\
\hline \multicolumn{4}{|l|}{ Comorbidities $^{a}$} \\
\hline No & 1.0 & 1.0 & 1.0 \\
\hline Yes & $0.57(0.29-1.12)$ & $3.97(1.30-12.1)^{*}$ & $0.38(0.12-1.24)$ \\
\hline \multicolumn{4}{|l|}{ Age, years } \\
\hline$<65$ & 1.0 & 1.0 & 1.0 \\
\hline$\geq 65$ & $0.32(0.15-0.69)^{*}$ & $1.24(0.38-4.07)$ & $0.58(0.17-2.01)$ \\
\hline \multicolumn{4}{|l|}{ Sex } \\
\hline Female & 1.0 & 1.0 & 1.0 \\
\hline Male & $2.61(1.31-5.19)^{*}$ & $2.36(0.77-7.25)$ & $1.22(0.42-3.52)$ \\
\hline \multicolumn{4}{|l|}{ Education, years } \\
\hline$<9$ & 1.0 & 1.0 & 1.0 \\
\hline $10-12$ & $1.31(0.56-3.09)$ & $0.54(0.13-2.24)$ & $0.43(0.09-2.04)$ \\
\hline$>12$ & $1.00(0.42-2.36)$ & $0.64(0.16-2.52)$ & $1.76(0.50-6.25)$ \\
\hline \multicolumn{4}{|l|}{ Marital status } \\
\hline Married & 1.0 & 1.0 & 1.0 \\
\hline Other & $1.90(0.93-3.86)$ & $0.13(0.02-1.06)$ & $0.27(0.06-1.27)$ \\
\hline \multicolumn{4}{|c|}{ Physical health awareness } \\
\hline Normal/Good & 1.0 & 1.0 & 1.0 \\
\hline Poor & $1.14(0.35-3.66)$ & $1.31(0.24-7.08)$ & $1.12(0.22-5.80)$ \\
\hline \multicolumn{4}{|c|}{ Mental health awareness } \\
\hline Normal/Good & 1.0 & 1.0 & 1.0 \\
\hline Poor & $0.64(0.25-1.64)$ & $1.23(0.32-4.80)$ & $1.17(0.29-4.71)$ \\
\hline \multicolumn{4}{|c|}{$\begin{array}{l}\text { Compliance with low } \\
\text { oil/sugar/sodium diet }\end{array}$} \\
\hline Never & 1.0 & 1.0 & 1.0 \\
\hline Often & $1.00(0.34-2.94)$ & $1.49(0.14-16.5)$ & $0.23(0.04-1.20)$ \\
\hline Always & $0.83(0.28-2.45)$ & $1.70(0.16-18.5)$ & $0.14(0.03-0.75)^{*}$ \\
\hline \multicolumn{4}{|c|}{ Use of dietary supplements } \\
\hline No & 1.0 & 1.0 & 1.0 \\
\hline Yes & $1.22(0.64-2.33)$ & $2.86(0.90-9.11)$ & $4.82(1.50-15.5)^{*}$ \\
\hline \multicolumn{4}{|l|}{ Sleeping time } \\
\hline$>7 \mathrm{~h}$ & 1.0 & 1.0 & 1.0 \\
\hline$<7 \mathrm{~h}$ & $0.90(0.46-1.79)$ & $4.68(1.42-15.4)^{*}$ & $1.47(0.51-4.30)$ \\
\hline Insomnia & $0.83(0.18-3.84)$ & $7.89(1.22-51.3)^{*}$ & $1.98(0.28-13.7)$ \\
\hline
\end{tabular}

\footnotetext{
a diabetes, kidney disease, or both. ${ }^{*} p<0.05$. OR, odds ratio. $\mathrm{CI}$, confidence interval.
}

In contrast, the use of dietary supplements was also associated with discontinuing medication $(\mathrm{aOR}=4.82,95 \% \mathrm{CI}=1.50-15.5)$. The different protective and risk factors for behaviors of medication nonadherence are summarized in Table 4 . 
Table 4. Summary of factors associated with specific behaviors of nonadherence to antihypertensive medication in this study, according to the multivariable logistic regression analysis.

\begin{tabular}{cccc}
\hline & \multicolumn{3}{c}{ Medication Nonadherence Behaviors } \\
\cline { 2 - 4 } Risk factors & Age $<65$ years & $\begin{array}{l}\text { Comorbidities (diabetes, } \\
\text { kidney disease, or both) }\end{array}$ & Discontinuing Medication \\
\cline { 2 - 4 } & Male sex & Insomnia & Compliance with low \\
Protective factor & & oil/sugar $/$ sodium diet \\
\hline
\end{tabular}

\section{Discussion}

This study investigated the association between specific behaviors related to medication nonadherence and different demographic, lifestyle, and clinical variables among hypertensive patients in Taiwan. Overall, the major medication noncompliant behavior exhibited by participants was forgetting to take medication. Age $<65$ years, male sex, presence of comorbidities, insomnia, and use of dietary supplements were risk factors for different nonadherence behaviors. Adequate compliance with a low oil/sugar/sodium diet was a protective factor for discontinuing the medication.

In this study, we found that $<65$ years of age was related to forgetting to take medication, which was consistent with the results of previous studies $[2,12,13]$. We speculate that younger patients are more prone to nonadherence due to a high work burden and a lack of an appropriate sense of illness. Previous research was conflicting regarding sex-related differences in antihypertensive medication compliance, with some studies showing a higher risk of nonadherence in women $[2,8,13]$ and others showing no difference between the sexes $[12,14]$. However, our findings showed that men were more likely to forget taking medication. Lin et al. [17] found that compared to female patients, male patients with diabetes were associated with poorer medication adherence, and another study found that the male patients in Taiwan had lower adherence to daily food guides [18]. Additionally, measurements of medication nonadherence in previous studies consisted of pill counts or scores in scales, which are different from our assessments. Further studies are required to elucidate sex-related differences in medication adherence.

Despite the fact that diabetes, kidney disease, or both were the sole comorbidities assessed in this study, we found that these were associated with a higher risk of reducing the medication dose. As expected, hypertensive patients with comorbidities took a higher number of drugs and required multiple doses more frequently than hypertensive patients without comorbidities. A study analyzing the health system data of Midwestern Americans found that the number of comorbidities present and the number of drugs taken were directly associated with poorer medication adherence [13]. Gupta et al. [2] came to a similar conclusion using drug metabolite assessments as indicators of medication nonadherence in British and Czech populations.

In this study, sleep disorders were associated with medication nonadherence; insomnia, in particular, significantly increased the likelihood of reducing the medication dose. This is consistent with the results of previous studies $[19,20]$. Additionally, we found that using dietary supplements was associated with a 4.82-fold increase in the risk of discontinuing medication, compared with not using dietary supplements, which is in line with the results from previous studies showing that hypertensive patients who use complementary and alternative therapies have low adherence to antihypertensive medication [11,15]. Furthermore, our study found that adequate compliance with a low oil/sugar/sodium diet was associated with good medication adherence. The link between a high salt diet and poor antihypertensive medication compliance has been described in previous studies [12,21], and Abu et al. [22] showed that patients with little knowledge of hypertension are likely to not restrict their salt intake. These findings suggest that interventions directed 
at increasing health literacy and encouraging lifestyle modifications could be useful in improving medication adherence in hypertensive patients.

To the best of our knowledge, few studies have investigated the factors associated with specific behaviors of medication nonadherence. Our study provides valuable information that may help medical staff accurately design education programs and interventions to improve the adherence of hypertensive patients to medication. However, this study has several limitations. Since data were collected through interviews and consisted of selfreports, social-desirability bias and recall bias are a concern. Besides, the health literacy of hypertensive patients may have been a confounding factor in this study. Additionally, as diabetes, kidney disease, or both are the sole comorbidities assessed in this study, the medical nonadherence of hypertensive patients with other comorbidities needs to be evaluated. Finally, since the characteristics of patients from hospitals in southern Taiwan may differ from those of patients from other hospitals or clinics, our results may not be generalizable to other districts.

Previous research has shown that adherence to antihypertensive medications is directly associated with a high quality of care, but not with the amount of time the medical staff spends with the patients [23]. Therefore, we believe that, in order to prevent nonadherence with antihypertensive treatment, healthcare providers should improve their communicative skills, implement tailored education programs, and generate specific interventions aimed at increasing commitment to therapy, especially in young patients with multiple comorbidities. Further investigations are required to find the impact of communication with hypertensive patients in their medication adherence.

\section{Conclusions}

In this study, the most common medication nonadherence behavior among patients with hypertension was forgetting to take medication. Age $<65$ years, male sex, the presence of comorbidities, insomnia, and the use of dietary supplements were risk factors for nonadherence to antihypertensive medication, whereas compliance with a low oil/sugar/sodium diet was associated with a lower risk of discontinuing medication.

Supplementary Materials: The following are available online at https:/ / www.mdpi.com/article/10 .3390/ijerph18189614/s1, Figure S1: The questionnaire.

Author Contributions: Conceptualization, S.-M.C., I.-C.L., and Y.-C.C.; methodology, Y.-C.C., S.M.C., and H.-Y.C.; formal analysis and investigation, S.-M.C., C.-F.H., and Y.-J.L.; data curation, Y.-J.L. and Y.-C.C.; writing-original draft preparation, S.-M.C., I.-C.L., and Y.-C.C.; writing-review and editing, H.-Y.C., C.-F.H., and Y.-C.C.; supervision, S.-M.C. and Y.-C.C.; project administration, S.-M.C. and Y.-C.C. All authors have read and agreed to the published version of the manuscript.

Funding: This research was funded by E-Da Hospital, grant number EDAHT109004.

Institutional Review Board Statement: The study was conducted according to the guidelines of the Declaration of Helsinki and approved by the Research Ethics Committee of E-Da Hospital (approval No. EMRP-108-065).

Informed Consent Statement: Informed consent was obtained from all subjects involved in the study. Data Availability Statement: Not applicable.

Acknowledgments: We gratefully acknowledge all the participants and interviewers in this study.

Conflicts of Interest: The authors declare no conflict of interest.

\section{References}

1. Whelton, P.K.; Carey, R.M.; Aronow, W.S.; Casey, D.; Collins, K.J.; Himmelfarb, C.D.; DePalma, S.M.; Gidding, S.; Jamerson, K.A.; Jones, D.W.; et al. 2017 ACC/AHA/AAPA/ABC/ACPM/AGS/APhA/ASH/ASPC/NMA/PCNA guideline for the prevention, detection, evaluation, and management of high blood pressure in adults: Executive summary: A report of the American college of cardiology / American heart association task force on clinical practice guidelines. Hypertension 2018, 71, 1269-1324. [CrossRef]

2. Gupta, P.; Patel, P.; Štrauch, B.; Lai, F.Y.; Akbarov, A.; Marešová, V.; White, C.M.; Petrak, O.; Gulsin, G.; Patel, V.; et al. Risk factors for nonadherence to antihypertensive treatment. Hypertension 2017, 69, 1113-1120. [CrossRef] 
3. Cimmaruta, D.; Lombardi, N.; Borghi, C.; Rosano, G.; Rossi, F.; Mugelli, A. Polypill, hypertension and medication adherence: The solution strategy? Int. J. Cardiol. 2018, 252, 181-186. [CrossRef]

4. $\quad$ Feng, Y.; Zhao, Y.; Yang, X.; Li, Y.; Han, M.; Qie, R.; Huang, S.; Wu, X.; Zhang, Y.; Wu, Y.; et al. Adherence to antihypertensive medication and cardiovascular disease events in hypertensive patients: A dose-response meta-analysis of 2769700 participants in cohort study. Qjm Int. J. Med. 2021, hcaa349. [CrossRef]

5. James, P.A.; Oparil, S.; Carter, B.L.; Cushman, W.C.; Himmelfarb, C.D.; Handler, J.; Lackland, D.T.; Lefevre, M.L.; MacKenzie, T.D.; Ogedegbe, O.; et al. 2014 evidence-based guideline for the management of high blood pressure in adults: Report from the panel members appointed to the Eighth Joint National Committee (JNC 8). JAMA 2014, 311, 507-520. [CrossRef] [PubMed]

6. Mancia, G.; Fagard, R.; Narkiewicz, K.; Redón, J.; Zanchetti, A.; Böhm, M.; Christiaens, T.; Cífková, R.; De Backer, G.; Dominiczak, A.; et al. $2013 \mathrm{ESH} / \mathrm{ESC}$ guidelines for the management of arterial hypertension: The task force for the man-agement of arterial hypertension of the European Society of Hypertension (ESH) and of the European Society of Cardiology (ESC). J. Hypertens. 2013, 31, 1281-1357. [CrossRef]

7. Chang, T.E.; Ritchey, M.D.; Park, S.; Chang, A.; Odom, E.C.; Durthaler, J.; Jackson, S.L.; Loustalot, F. National rates of nonadherence to antihypertensive medications among insured adults with hypertension, 2015. Hypertension 2019, 74, 1324-1332. [CrossRef]

8. Abegaz, T.M.; Shehab, A.; Gebreyohannes, E.A.; Bhagavathula, A.S.; Elnour, A. Nonadherence to antihypertensive drugs: A systematic review and meta-analysis. Medicine 2017, 96, e5641. [CrossRef] [PubMed]

9. Wu, P.-H.; Yang, C.-Y.; Yao, Z.-L.; Lin, W.-Z.; Wu, L.-W.; Chang, C.-C. Relationship of blood pressure control and hospitalization risk to medication adherence among patients with hypertension in Taiwan. Am. J. Hypertens. 2010, 23, 155-160. [CrossRef] [PubMed]

10. Abbas, H.; Kurdi, M.; de Vries, F.; van Onzenoort, H.; Driessen, J.H.; Watfa, M.; Karam, R. Factors associated with antihypertensive medication non-adherence: A cross-sectional study among Lebanese hypertensive adults. Patient Prefer. Adherence 2020, 14, 663-673. [CrossRef]

11. Gohar, F.; Greenfield, S.M.; Beevers, D.G.; Lip, G.Y.H.; Jolly, K. Self-care and adherence to medication: A survey in the hypertension outpatient clinic. BMC Complement. Altern. Med. 2008, 8, 4. [CrossRef]

12. Choi, H.Y.; Oh, I.J.; Lee, J.A.; Lim, J.; Kim, Y.S.; Jeon, T.-H.; Cheong, Y.-S.; Kim, D.-H.; Kim, M.-C.; Lee, S.Y. Factors affecting adherence to antihypertensive medication. Korean J. Fam. Med. 2018, 39, 325-332. [CrossRef]

13. Rolnick, S.J.; Pawloski, P.; Hedblom, B.D.; Asche, S.E.; Bruzek, R.J. Patient Characteristics Associated with Medication Adherence. Clin. Med. Res. 2013, 11, 54-65. [CrossRef]

14. Lee, G.K.Y.; Wang, H.H.; Liu, K.Q.L.; Cheung, Y.; Morisky, D.E.; Wong, M.C.S. Determinants of medication adherence to antihypertensive medications among a Chinese population using Morisky medication adherence scale. PLoS ONE 2013, 8, e62775. [CrossRef]

15. Krousel-Wood, M.A.; Muntner, P.; Joyce, C.J.; Islam, T.; Stanley, E.; Holt, E.W.; E Morisky, D.E.; He, J.; Webber, L.S.; Morisky, D.E. Adverse effects of complementary and alternative medicine on antihypertensive medication adherence: Findings from the cohort study of medication adherence among older adults. J. Am. Geriatr. Soc. 2010, 58, 54-61. [CrossRef]

16. Morisky, D.E.; Ang, A.; Krousel-Wood, M.; Ward, H.J. Predictive validity of a medication adherence measure in an outpatient setting. J. Clin. Hypertens. 2008, 10, 348-354. [CrossRef]

17. Lin, C.-S.; Khan, H.; Chang, R.-Y.; Liao, W.-C.; Chen, Y.-H.; Siao, S.-Y.; Hsieh, T.-F. A study on the impact of poor medication adherence on health status and medical expense for diabetes mellitus patients in Taiwan: A longitudinal panel data analysis. Medicine 2020, 99, e20800. [CrossRef]

18. Li, M.-C.; Fang, H.-Y. Adherence to daily food guides is associated with lower risk of metabolic syndrome: The nutrition and health survey in Taiwan. Nutrients 2020, 12, 2955. [CrossRef] [PubMed]

19. Khalesi, S.; Irwin, C.; Sun, J. Dietary patterns, nutrition knowledge, lifestyle, and health-related quality of life: Associations with anti-hypertension medication adherence in a sample of Australian adults. High Blood Press. Cardiovasc. Prev. 2017, $24,453-462$. [CrossRef] [PubMed]

20. Marcum, Z.A.; Zheng, Y.; Perera, S.; Strotmeyer, E.; Newman, A.B.; Simonsick, E.M.; Shorr, R.I.; Bauer, D.C.; Donohue, J.M.; Hanlon, J.T. Prevalence and correlates of self-reported medication non-adherence among older adults with coronary heart disease, diabetes mellitus, and/or hypertension. Res. Soc. Adm. Pharm. 2013, 9, 817-827. [CrossRef] [PubMed]

21. Natarajan, N.; Putnam, W.; Van Aarsen, K.; Lawson, K.B.; Burge, F. Adherence to antihypertensive medications among family practice patients with diabetes mellitus and hypertension. Can. Fam. Physician Med. Fam. Can. 2013, 59, e93-e100.

22. Abu, H.O.; Aboumatar, H.; Carson, K.A.; Goldberg, R.; Cooper, L.A. Hypertension knowledge, heart healthy lifestyle practices and medication adherence among adults with hypertension. Eur. J. Pers. Centered Health 2018, 6, 108-114. [CrossRef]

23. Fortuna, R.J.; Nagel, A.; Rocco, T.A.; Legette-Sobers, M.S.; Quigley, D. Patient experience with care and its association with adherence to hypertension medications. Am. J. Hypertens. 2018, 31, 340-345. [CrossRef] [PubMed] 